\title{
Reasons for application and expectations from a post-registration degree: Views of Omani nurses and their managers
}

\author{
Dianne Sheryl Watkins, Jane Louise Ryan \\ School of Health Care Sciences, Cardiff University, Cardiff, United Kingdom
}

Received: December 10, 2014

Accepted: January 8, 2015

Online Published: February 12, 2015

DOI: $10.5430 /$ jnep.v5n4p115

URL: http://dx.doi.org/10.5430/jnep.v5n4p115

\begin{abstract}
Introduction: A BSc in Nursing Studies for qualified nurses has been delivered in Oman by Cardiff University since 2009. Research was undertaken to explore why Omani nurses applied and expectations from the programme. It also investigated managers' reasons for sending nurses on the degree and their expectation of nurses on completion.

Design: A longitudinal qualitative research study followed nurses in 2 cohorts $(\mathrm{N}=27+30)$ and a selection of their managers $(\mathrm{N}=20)$. Data collection took place at various sites throughout Oman.

Methods: Focus groups were undertaken with all nurses who embarked on the programme. Semi structured interviews took place with a random selection of ten nurses and their managers from each cohort ( $\mathrm{N}=20$ nurses/20 nurse managers) 6 months after the course had completed. Thematic analysis was undertaken using a template developed from data.

Results: Nurses' reasons for application included easy access to a degree in Oman; career aspiration and progression; knowledge and skill acquisition; self-growth; gain a qualification and prepare for postgraduate study. They expected to learn skills of English language, critical analysis and application of evidence to practice. Managers sent nurses to enhance personal and professional development; change practice; improve quality of patient care and develop nursing as a profession in Oman.

Conclusion: The delivery of a degree by a UK institution taught in English at an institution abroad has advantages. It increases accessibility; maintains family and social network connections; offers familiarity with cultural norms; and facilitates entry into the academic world of English written literature. These factors facilitate nurses' developing skills and knowledge to underpin practice and the profession with evidence; highlighting the benefits of transnational programmes.
\end{abstract}

Key Words: Evidence based practice, Curriculum development, Transnational education, Oman

\section{Introduction}

Nursing in Oman first developed in the 1950s and was officially recognised as a profession in 1972, with the establishment of a Directorate of Nursing at the Ministry of Health $(\mathrm{MoH})$. A modernisation programme has been in place to reduce the country's dependence on expatriates leading the profession, and to educate Omani nurses to degree and Masters level. Historically nurses have been sent abroad to gain degrees, returning to positions in education or administration, with limited numbers returning to clinical practice. In 2008 the number of nurses holding a Bachelor's degree was

\footnotetext{
*Correspondence: Dianne Sheryl Watkins; Email: watkinssd@ cardiff.ac.uk; Address: School of Health Care Sciences, Cardiff University, Cardiff, United Kingdom. 
approximately 180 with around 40 nurses possessing a Master's degree. ${ }^{[1]}$ Plans are to increase the numbers of nurses with degrees in all areas of nursing.

In 2007 discussions took place between the Cardiff University, the Oman Specialised Nursing Institute (OSNI) and the $\mathrm{MoH}$ to develop a BSc (Hons) in Nursing for qualified nurses. In May 2009 the first cohort commenced a full time one year 'top up degree' offering 120 credits at level 6 for qualified nurses who already hold a diploma. Level 6 equates to the third year in an undergraduate first degree programme. This offers a Cardiff University award, and the teaching component is delivered by staff from Cardiff University on site in Oman. Staff from OSNI mentor students, act as personal tutors, and undertake formative assessments. All academic supervision and marking is carried out by (name held for peer review) staff. The project is funded by the $\mathrm{MoH}$ with the aim of enhancing nursing practice, improving evidence based patient care and investing in the human resource of its country.

A research study funded by the MoH Oman and (name held for peer review) was undertaken to explore why Omani nurses chose to undertake a BSc; and investigated nurses' and nurse managers' expectations from the programme.

\subsection{Literature review}

European studies indicate that nurses engage in education post qualification for personal and professional reasons. ${ }^{[2-8]}$ The latter includes upgrading an initial qualification; keeping abreast with global and local developments in the profession; gaining promotion; enhancement of their career; improving knowledge and performance at work; seeking academic credibility; and taking forward the profession to enhance care. ${ }^{[2,4-6,9-11]}$

Spencer ${ }^{[6]}$ undertook a study to examine personal reasons for undertaking Masters study and found that a large majority of participants did so to intellectually stimulate themselves and to keep up to date with nursing development. Free fees also act as an incentive; gaining access to a speciality through degree study; and "professional survival" are classed as major reasons for undertaking a degree postqualification. ${ }^{[10]}$

The accessibility and availability of study increases nurses' personal motivation and degrees hosted overseas by UK institutions are seen as advantageous. Malaysian nurses undertook a degree offered by an Australian University to "enhance their career prospects, work related stimulation, selfgrowth and personal achievement". [3]

Reasons why nurses apply to undertake a degree relate to perceived outcomes, such as the development of research skills and an increase in confidence. Confidence gained post degree programme can only be described as "finding a voice of my own and materialises when nurses feel con- fident in advising others, articulating the nature of nursing, trying new ways of working and not being afraid to take chances". [5, 12]

A major reason for nurses applying for and undertaking post registration courses is they perceive it will make a difference to practice and examples to evidence this are speculative and unsubstantiated. ${ }^{[2,6,7]}$ Much of the research refers to nurses' self-perception of their value, post degree. ${ }^{[7]}$ This should not be underestimated as improvements in personal confidence, cognitive functioning, and evidence based practice development may positively influence patient care. ${ }^{[11]}$

UK nurses' access to degrees post-registration is often controlled by nurse managers who act as "gate keepers. Necessity for education is not always determined appropriately and may not relate to nurses' personal requirements for CPD or the needs of the organisation". ${ }^{[5,13,14]}$ How this is determined or what is expected from degree level nurses postcompletion in unknown in the Middle East and many other parts of the developing world. Such information would assist Higher Education Institutes in planning transnational education curricula for qualified nurses across the globe.

\subsection{Research aims}

(1) To explore why Omani nurses apply to undertake a BSc (Hons) in Nursing Studies and their expectations from the programme;

(2) To investigate why Omani nurse managers send nurses on a BSc (Hons) in Nursing Studies and their expectations of nurses on completion.

\section{Method}

\subsection{Research design}

A longitudinal design was adopted and allowed data collection at "two or more points in time"; ${ }^{[15]}$ such a research design features in two recent studies. ${ }^{[16,17]}$ Two cohorts were followed over a period of 18 months commencing May 2010 and completing November 2012. Data were collected from cohorts at the end of the BSc programme and 6 months following completion. In longitudinal research the researcher is committed to studying the subject matter whilst having an awareness of possible variables, and consideration for how they will be measured prior to collection and interpretation of the data. ${ }^{[18]}$ The longitudinal design allowed a developmental insight into changes in participants' perceptions of degree level study over time. ${ }^{[15]}$

\subsection{Sample}

The total population of Omani nurses who undertook the degree programme during the time frame 2009 - 2011 totalled 57; 27 in cohort 1 and 30 in cohort 2. All were approached to participate in the study. Purposive sampling was considered suitable, as participants were representative of the 
population under study. ${ }^{[19]}$ All 57 nurses were given the opportunity to partake in focus groups; 10 nurses from each cohort were selected for interview using the simple random sampling method. Potential participants were randomly selected from the sampling frame. ${ }^{[15]}$

In addition, twenty managers were selected for interview because they were line managers to nurses who had undertaken the programme. 10 of these were managers to nurses in cohort 1 and 10 managers to nurses in cohort 2.

\subsection{Data collection}

A series of focus groups took place with nurses in each cohort on completion of the programme. Six months later semi structured interviews took place with a random sample of 10 nurses. In addition, semi-structured interviews were undertaken with 20 nurse line managers. A combination of data collection methods were employed to help validate the data. The focus groups and interviews were undertaken by researchers involved in the project team and discussion took place between team members to ensure consistency in approach and questioning in data collection. All focus groups and interviews were tape recorded and transcribed.

A focus group schedule was developed which aimed to extract data to answer the research questions posed. Questions asked in the focus groups and semi structured interviews related to reasons for application and expectations from the programme. Nurse managers were questioned on how they selected students for the programme and their expectations of the degree level nurse on return to practice.

The focus groups yielded rich data and were "co-produced" by the interaction between the researchers and the participants. $^{[20]}$ The data from the focus groups helped inform semi structured interview schedules for use with both nurses and managers. ${ }^{[19]}$ Focus groups took place in OSNI where nurses had attended the course. Interviews were conducted usually at the nurses or managers place of work, where a quiet room free from interruptions had been previously arranged. This was considered easier for participants and to positively influence response rates. Focus groups and interviews were conducted in English and some cross cultural difficulties were experienced associated with expression of thought and noted to have an effect on the depth of answers given. ${ }^{[8,21,22]}$

\subsection{Ethical issues}

The study proposal was quality approved by (name held for peer review) Research Review and Ethics Committee. Ethical approval was granted from the Cardiff University Ethics Committee and approval granted by the $\mathrm{MoH}$ and the Research Committee in Oman. Participation in the study was voluntary. Invited nurses and nurse managers received information pertaining to the study.

Consent was obtained prior to data collection. Confiden- tiality was assured during data collection and the reporting processes. All information pertaining to the study was kept in a secure environment accessible only by the researchers. The legal requirements associated with the Data Protection Act 2000 were adhered to.

\subsection{Data analysis}

A framework was used to guide data analysis based on the work of Crabtree \& Miller. ${ }^{[23]}$ This is described as "template, editing and immersion/crystalisation". A coding template was devised from a preliminary scan of the transcripts and the literature reviewed, and emerging themes identified. ${ }^{[23]}$ Data from all focus groups and interviews were combined. Text from the data were coded and placed under the themes; text that fell outside of the themes was coded miscellaneous. The use of a template or code manual may be more focused and time efficient than other organising styles. The interpreter is able to focus on particular aspects of the text and does not delve into the tedious effort of intense line by line scrutiny. ${ }^{[23]}$

The coded transcripts were cross checked by a researcher not involved in the initial content analysis to improve interreliability. Each themed area was colour coded in the text and transferred to a theme. The themed text was analysed and emerging findings categorised. The final themes that emerged in relation to reasons for application and expectations were merged as many of the reasons overlapped. The final themes were:

(1) Geographical location of the course;

(2) Career aspirations;

(3) Knowledge and skills acquisition;

(4) Improve practice and quality of patient care.

\section{Results}

\section{Biographical profile}

Cohort 1: 24 out of 30 students took part in focus groups. 10 students and 10 nurse managers were interviewed. Cohort 2: 21 out of 27 students took part in the first focus group; 17 out of 27 partook in the second focus group. All 10 students and nurse managers attended for interview. All students held a diploma qualification on entry to the programme and an IELTS score of 6.5. Nurse managers interviewed were at varying stages in their professional career; not all held a degree.

Quotes from the data have been coded as originating from cohort 1, focus group or interview (C1, FG or I); cohort 2, focus group 1 or 2 or interview (C1, FG1 or 2, C2, I).

\section{Theme A - Geographical location}

Nurses felt it was a distinct advantage being able to attend a degree from a British University delivered in Oman and 
this influenced reasons for application. A large percentage of students had children and studying in Oman prevented separation from family life as the following quote indicates:

\begin{abstract}
"Because it is in our country, we don't have to travel a long journey Not only that it is very difficult to leave a family, the children - very difficult for someone else to take care of them. Leave your family, kids, difficult to move from one place to another. A course in this country is a big opportunity for us. I consider these are considerations and factors that influence learning. For me, a mother will not learn effectively if parted from her children?" (SI 6, cohort 1)
\end{abstract}

This was confirmed by nurse managers who indicated the advantage of having a BSc run in Oman.

"They actually leave the country to go abroad, and we need these particular people because they have been excellent in their own specialities, in general nursing, service here in the country, so it was important to think about them and make the education available for them here." (NM 10, Cohort 1)

\section{Theme B - Career aspirations and self-growth}

Students applied because they thought it would enhance their professional career. Aspirations were fuelled by knowledge that nurses require a degree to obtain promotion and be accepted onto Masters level study.

\begin{abstract}
"When I first applied I was thinking of my career. I mean to develop and in my position I have to go through the BSc course to get the Masters degree." (C1, FG1)

"It's a very nice opportunity for us, we can grow in our profession. I think it's a good opportunity to have a good post in the hospital." (C2, FG)
\end{abstract}

While a degree qualification aided promotion, students openly demonstrated they were proud to be enrolled on a BSc programme. The qualification was classed as a "badge of honour".

"In Oman, the majority of nurses have a diploma in nursing, now, how prestigious it is when you have a Bachelor." (C2, FG1)

Students applied to develop personally in the hope that the course would improve self-esteem and confidence. Many were motivated to apply and self-initiated their application. Another reason for application related to students wanting to improve mastery of the English language which they saw as an important part of self-growth. This was highlighted by a student discussing an ex student from cohort 1 ,

"There is one nurse that came after the BSc, she presented some lectures. She was confident. Her language was perfect; she was mature, compared with us who didn't yet do the BSc. That motivated us to join the programme, to gain that confidence and maturity." (C2, FG 1)

\section{Theme C - Knowledge and skill acquisition}

Knowledge and skill acquisition were cited as major reasons for application and as expectations from the programme by students. This was closely related to improving professional development which included underpinning nursing with evidence, building on and updating previous knowledge, giving nursing a voice and improving practice.

"There is a very good chance to update our knowledge because in clinical practice, we are just working, the skills are there, but the theoretical part - not much there. To search and update your knowledge, studying is a very good chance, we would be relieved from the work, from responsibility - so we would be free to learn." (C1, I)

Students also applied because they wanted to positively influence patient care through accessing and interpreting evidence and utilising this to improve practice.

"I entered the BSc programme because first of all I like to learn. I wanted to change myself and client care, because many times I was challenged by many things. I couldn't look out for myself or the client care because I don't have evidence or a knowledge base." (C2, FG2)

"I have applied to develop and improve my knowledge and experience, because I thought after the diploma in nursing, I am thinking in one way only. I am not thinking about evidence based as I am thinking in this group now." (C1, 1)

Student's expectations were summarised as evidence based practice (EBP) which included critical thinking, critical analysis and problem solving. They expected to be challenged and to learn differently with a move towards more independent learning. The subject knowledge they expected to gain centred on leadership, management, information technology and exposure to new ideas. 
"So I want the power, I should have more knowledge to go to the internet, to critique the strong evidence about research and nursing." (C2, FG2)

"I expected to know how to critique, to critique a research paper. I expected to know when I am observing a problem in my clinical area, in my management. When there is something happening, I just go back and see where I messed up - am I going wrong or did I forget something." $(\mathrm{C} 1, \mathrm{I})$

\section{Theme D - Improve practice and quality of patient care}

On completion of the BSc. Managers expected nurses to teach junior staff, to be leaders and to influence the quality of patient care; however, the nurse managers' view was supported by nurses themselves.

"The reason for sending staff is mainly to help improve the care. I mean the nursing care in the hospital and also to increase the quality of care.” (NM, I)

"Developing myself professionally so that I can develop my clinical practice as well and convey - acquire skills - acquire knowledge to my colleagues - the more we know, the more we study, the more we know, opens our eyes to the nursing profession.” (C2, FG4)

"I expect them to gain better knowledge than what they have right now, and mostly we want them to be a person who comes back involved, imparting knowledge to their colleagues so that they can guide juniors, colleagues, in assuming a better quality in nursing care for patients. We want them to make changes, but when we make them a leader they should have the skills and knowledge and management skills in leadership to guide the department role well ... we would like to have someone ascending to come up with good knowledge and skills to manage their own department." (NM, I)

Nurses discussed expectations in relation to learning about doing things in a different way and underpinning practice with evidence.

"We expected to learn different knowledge and to utilise our own skills like critical thinking/analysing - to improve patient care and underpin with evidence.” (FG1, C1)

\section{Discussion}

The geographical location of the BSc programme held in Oman, led by staff from Cardiff University, and proved a distinct advantage for Omani nurses and managers. It was available and easily accessible, which proved a positive motivating factor for application to the programme, as highlighted in other research. ${ }^{[3,8]}$ Problems facing international students studying in the UK relate to social and academic transition. ${ }^{[24]}$ They experience homesickness, are often lonely, miss family and friends, and require emotional support from family units to achieve success on a programme. ${ }^{[10,25]}$ Nurses and managers in our study reinforced closeness to culture, social networks and family as reasons for application.

Developing proficiency in the English language was identified by students as an incentive and acted as a motivating factor for wanting to undertake the degree. Likewise: "the growing use of English as a medium of research and instruction, especially at graduate level, may stimulate interest in international programs, offered by Universities in English".[26]

Omani nurses cited career progression as a major reason for undertaking a BSc. as reported by Chiu, ${ }^{[3]}$ Spencer, ${ }^{[6]}$ Cooley. ${ }^{[10]}$ Nurses undertaking a post registration degree in Malaysia viewed it as an important step in gaining promotion. ${ }^{[3]}$ Studies indicate there is a correlation between degree level status and career enhancement, ${ }^{[6,11]}$ supported by managers in this study. Cultural differences were observed amongst Omani nurses; part of their motivation for application was financial, as achievement of a degree carries a salary increase irrespective of position. Nursing is developing rapidly in Oman, with importance placed on achievement of a degree. Rivalry exists over senior positions; nurses are keen to be promoted, hence competition to achieve academically is paramount to career progression. A similar UK perspective exists where "evidence of higher education was a pre-requisite for career progression", supported by findings from a study into German and UK nurses' motivation to undertake a master's degree. ${ }^{[6,8]}$

To develop professionally and clinically was an impetus for applying and a motive for managers agreeing to release of nurses to undertake the degree. Nurses implied that embarking on a degree would develop them as individuals within their working environment, able to teach and lead others. They expected to gain new and in-depth knowledge about subjects and underpin practice with evidence. This is mirrored by managers whose expectation was that nurses would return from a BSc programme able to lead and enhance the quality of patient care. Such a finding is echoed by Chiu ${ }^{[3]}$ who reports that Malaysian nurses envisaged a degree would broaden their knowledge and contribute to professional development. Such valued knowledge enables the student to extend their skills in clinical practice and underpin deci- 
sion making with evidence to support patient care. ${ }^{[6]}$ In an exploratory study by $\mathrm{Bahn}^{[9]}$ one student cited that 'academic study had changed them personally and professionally'. Nurses and managers in our study concluded that having evidence based knowledge to question clinical decisions and underpin care with appropriate research findings was a major expectation from the degree. The approach to use evidence based knowledge is likely to elevate the status of the nurse and hence the nursing profession. ${ }^{[27]}$

Improving and developing nursing practice was a motivating factor for application and an expectation from the programme. All Omani nurses anticipated they would acquire new knowledge and skills to critique, and appreciate how evidence strengthened their clinical care. Improving the quality of nursing practice was a major reason why nurse managers invested in qualified staff undertaking the BSc. Research indicates those who complete a degree postqualifying gain such skills and knowledge ${ }^{[6,11,28]}$ and benefits to patient care may be enhanced through development of nurses' professional and personal qualities. ${ }^{[7]}$ Correlation between educational level and patient outcomes has also been proven by Atkin et al. ${ }^{[29]}$ although this may not be generalisable across nursing specialities and contexts. In our study, it was reassuring to hear Omani nurses and managers discuss education linked with motivation to develop and improve practice. Giving nursing a voice and further enhancing the status of nursing as a profession in Oman was expressed by both managers and nurses, a view supported by Cardiff University, ${ }^{[11]}$ Gerrish et al. ${ }^{[30]}$ This has advantages to countries where nursing is in its infancy, working to achieve prominence and professional standing.

\section{Strengths and study limitations}

A strength of this study is the research collaboration between international organisations. The sample chosen were suitable to answer the research questions although findings cannot be generalised because of the sample size and geographical context in which the research was undertaken. An additional limitation is that three of the researchers were non arabic speakers and this may have impacted on the conversational exchange between researcher and participant, thus influencing the interperation and analysis of the data.

\section{Conclusion}

Omani nursing assumed a new status when it was recognised as a profession in 1972. The reliance on expatriates to lead the profession has had a detrimental effect on career progression of Omani nurses and possibly the number achieving a degree, coupled with the availability of educational programmes. The position has changed with a move towards Omanisation and thus investment in the country's nationals. The collaboration between Cardiff University and OSNI to grow a degree programme in Oman has contributed positively as to why nurses favour undertaking a degree in their own country. The delivery of a degree by a UK institution in Oman is seen as a distinct advantage in terms of increasing accessibility and closeness to cultural norms and values. This is not to say that the "uncritical transfer" of UK curriculum without due regard to culture and context should take place; however there are expectations from nurses and managers mirrored across nations which can be reflected in transnational curricula. Creating a platform for career enhancement and developing leadership; learning the skills to access and critically analyse information; improving competence at English language which opens up the academic world of English written literature, are considered vital to underpin improvement and development of nursing practice. This reflects the ethos of the $\mathrm{MoH}$ and is an investment in modernising and further developing the nursing profession in Oman. This transnational educational programme between two collaborating institutions meets a need for nurses' continuing professional education and will enhance the future status and professionalisation of nursing in the Sultanate of Oman.

\section{Conflicts of Interest Disclosure}

The author declares that there is no conflict of interest statement.

\section{References}

[1] Alghemini M, Denham SA. Professional Nursing in Oman. Minority Nurse Writer. 2008. Available from: http://www . minoritynu rse.com/article/professional-nursing-oman

[2] Hardwick S, Jordan S. The impact of part-time post registration degrees on practice. Journal of Advanced Nursing. 2002; 38(5): $524-$ 535. PMid:12028286 http://dx.doi.org/10.1046/j.1365-2 $648.2002 .02214 . x$

[3] Chiu LH. Motivation for nurses undertaking a post-registration qualification in Malaysia. International Nursing Review. 2005; 52: 4651. PMid:15725276 http://dx.doi.org/10.1111/j.1466-7 $657.2004 .00415 . x$
[4] Nolan M, Owen R, Curran M, et al. reconceptualising the outcomes of continuous Professional Development, International Journal of Nursing Studies. 2000; 37: 457-467. http://dx . doi .org/10.10 16/S0020-7489(00)00025-0

[5] Ellis E, Nolan M. Illuminating continuing professional education; unpacking the black box. International Journal of Nursing Studies. 2005; 42: 97-106. PMid:15582643 http://dx.doi.org/10.10 16/j.ijnurstu.2004.05.006

[6] Spencer RL. Nurses', midwives' and health visitors' perceptions of the impact of higher educationon in professional practice. Nurse Education Today. 2006; 26: 45-53. PMid:16122844 http://dx.doi . org/10.1016/j.nedt . 2005.06.006

[7] Cotterill-Walker SM. Where is the evidence that master's level nurs- 
ing education makes a difference to patient care? A literature review. Nurse Education Today.2012; 32: 57-64. PMid:21371793 http://dx.doi.org/10.1016/j.nedt.2011.02.001

[8] Dianne W. Motivation and expectations of German and British nurses embarking on a Masters programme. Nurse Education Today. 2011; 31: 31-35. PMid:20398982 http://dx.doi.org/10. 1016/j.nedt. 2010.03.009

[9] Bahn D. Reasons for post registration learning: Impact of the learning experience. Nurse Education Today. 2007; 27: 715722. PMid:17126455 http://dx.doi.org/10.1016/j.nedt. 2006.10 .005

[10] Cooley MC. Nurses' motivation for studying third level postregistration nursing programmes and the effects of studying on their personal and work lives. Nurse Education Today. 2008; 28: 588-594. PMid:18313177 http://dx.doi.org/10.1016/j.ned t. 2007.11 .002

[11] Dianne Watkins. The influence of Masters education on the professional lives of British and German nurses and the further professionalization of nursing. Journal of Advanced Nursing. 2011; 67(12): 2605-2614. PMid:21615461 http://dx.doi.org/10.1111/j.1 365-2648.2011.05698.x

[12] Crooks D, Carpio B, Brow B, et al. Development of professional confidence by post diploma baccalaureate nursing students. Nurse Education in Practice. 2005; 5: 360-367. PMid:19040846 http: //dx.doi.org/10.1016/j.nepr.2005.05.007

[13] Gould D, Drey N, Berridge EJ. Nurses' experiences of continuing professional development. Nurse Education Today. 2007; 27: 602-609. PMid:17109999 http://dx.doi.org/10.1016/j.ned t.2006.08.021

[14] Drennan J, Hyde A. Social selection and professional regulation for master's degrees for nurses. Journal of Advanced Nursing. 2008; 63(5): 486-493. PMid:18727751 http://dx.doi.org/10.1111 /j.1365-2648.2008.04730.x

[15] Polit DF, Beck CT, Hungler BP. Essentials of Nursing Research: methods, appraisal, and utilization. Sixth Edition, Philadelphia, J.B Lippincott Comapany. 2006.

[16] Rudman A, Gustavsson JP. Burnout during Nursing Education predicts lower occupational preparedness and future clinical performance: A longidutinal study. International Journal of Nursing Studies. 2012; 49(8): 988-1001. PMid:22542085 http://dx.doi.org /10.1016/j.ijnurstu. 2012.03.010

[17] Sun FK, Chiang CY, Lin CH. A suicide Education programme for nurses to educate the family caregivers of suicidal individuals: A longitudinal study. Nurse Education Today. 2013; 33(10): 1192 1200. PMid:22818226 http://dx.doi.org/10.1016/j.nedt. 2012.06 .017
[18] Burns N, Grove SK. The Practice of Nursing Research Conduct, Critique, \& Utilization. Fifth Edition, Philadelphia, W.B. Saunders Company. 2005.

[19] Richards L, Morse JM. Read Me First for a User's Guide to Qualitative Methods, Second Edition, London, Sage publications. 2007.

[20] Robinson J. Using focus groups, in Delamont, S. (ed) Handbook of Qualitative Research in Education, Cheltenham, Edward Elgar Publishing Limited. 2012. http://dx.doi.org/10.4337/9781849 807296.00037

[21] Ryen A. Cross cultural interviewing. In Holstein, J. A. and Gubrium, S. (eds) Inside Interviewing: New Lenses, New Concerns, Thousand Oaks, Sage. 2003; 429-448.

[22] Jane R, Yahya MS, Gillian W, et al. Respecting the culture: undertaking focus groups in Oman. Qualitative Research. 2014.

[23] Crabtree B, Millar W. (Eds) Doing Qualitative Research, Thousand Oaks, Sage. 1999.

[24] Andrade MS. International students in English-speaking Universities: Adjustment factors. Journal of Research in International Education. 2006; 5: 131-153. http://dx.doi.org/10.1177/14752 40906065589

[25] Rajapaksa S, Dundes L. It's a long way home: International student adjustment to living in the United States. College Student Retention. 2002; 4(1): 15-28. http://dx.doi.org/10.2190/5HCY-U 2Q9-KVGL-8M3K

[26] Altbach PG, Knight J. The Internationalization of Higher Education: Motivations and Realities. Journal of Studies in International Education. 2007; 11: 290. http://dx.doi.org/10.1177/1028315 307303542

[27] Tumulty G. Professional Development of Nursing in Saudi Arabia. Journal of Nursing Scholarship. Third Quarter. 2001; 285-290. PMid: 11552557

[28] Griscti O, Jacocono J. Effectiveness of continuing education programmes in nursing: literature review. Journal of Advanced Nursing. 2006; 55(4): 449-456. PMid:16866840 http://dx.doi.org /10.1111/j.1365-2648.2006.03940.x

[29] Atkin L, Currey J, Marshall A, et al. Discrimination of educational outcomes between differing levels of critical care programmes by selected stakeholders in Austalia: a mixed method approach. Intensive and Critical Care Nursing. 2008; 24(2): 68-77. PMid:17942310 http://dx.doi.org/10.1016/j.iccn.2007.09.001

[30] Gerrish K, Ashworth PD, McManus M. Creating what sort of professional? Master's level nurse education as a professionalising strategy. Nursing Inquiry. 2003; 10(2): 103-112. PMid:12755859 http://dx.doi.org/10.1046/j.1440-1800.2003.00168.x 